\title{
ARTICLE
}

\section{Emerging Contaminants in Aqueous Matrices Determined by Gas Chromatography-Mass Spectrometry}

\author{
Emerson Luis Yoshio Hara' ${ }^{\text {(D) }}$, Barbara Gomes Souza Soares ${ }^{1}$ iD, Adriano Lucas Paiva dos
} Santos $^{1}$ (D), Bruno José Gonçalves da Silva ${ }^{1}$ D, Gilberto Abate ${ }^{1}$ (D), Kelly Cavalcanti Machado ${ }^{2}$ iD, Beatriz Isabella Cestaro ${ }^{1}$ iD, Rafael Garrett Dolatto ${ }^{1}$ iD, Marco Tadeu Grassi ${ }^{1 *}$ D $\square$

${ }^{1}$ Departamento de Química, Grupo de Pesquisa em Química Ambiental, Universidade Federal do Paraná, Rua Francisco H. dos Santos, 100, Jardim das Américas, Curitiba, Paraná, 81531-980, Brazil

${ }^{2}$ Instituto Carlos Chagas/Fundação Osvaldo Cruz Paraná, Rua Professor Algacyr Munhoz Mader, 3775 , Cidade Industrial de Curitiba, Curitiba, PR, 81310-020, Brazil

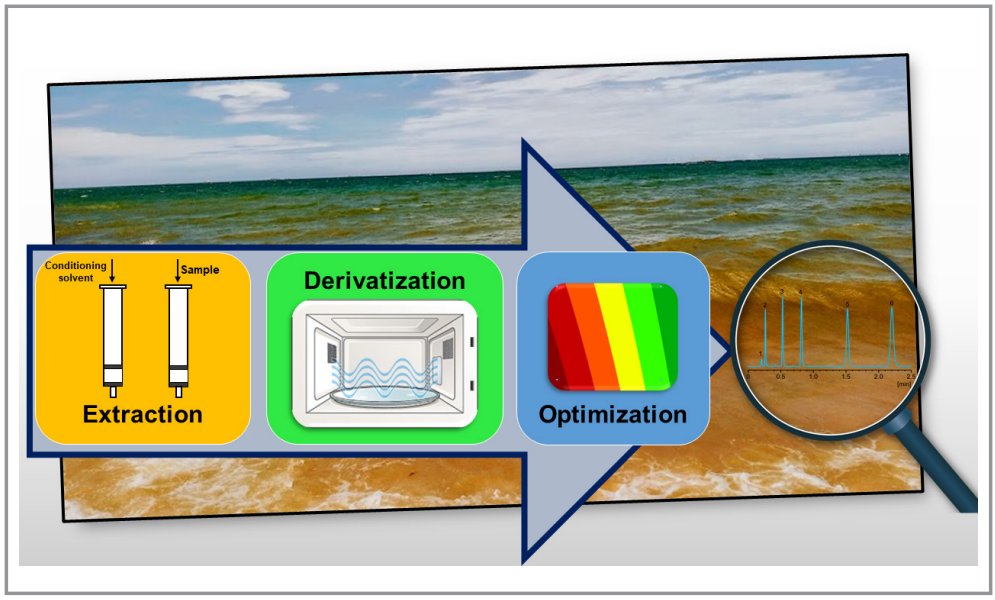

Reports on the determination of emerging contaminants (EC) in aqueous samples have been increasingly common. Due to the low levels of concentration of the analytes as well as the complexity of this matrix, the analysis is done preferably by liquid chromatography (LC). Owing to the polar character of most of the EC determination by gas chromatography is deprecated. One way to overcome this barrier is through derivatization, which, in some cases, can be a lengthy step, presents risks to the analyst as well as to the environment due to the toxicity of the derivatizing agent, and, thus, ends up favoring the use of LC. An analytical protocol was developed in this work to increase the efficiency of derivatization in a shorter reaction time for the determination of ibuprofen, 4-octylphenol, 4-nonylphenol, triclosan, bisphenol A, diclofenac, estrone, 17- $\beta$-estradiol, estriol, coprostanol, and cholesterol. The proposal then was to carry out the silylation reaction of the analytes with the aid of a domestic microwave oven. The results indicated that the use of the device provided an increase in the efficiency of the reaction, due to the homogeneous heating of the solution. Besides, there was a significant decrease in the derivatization time of the analytes from $30 \mathrm{~min}$ to $5 \mathrm{~min}$. Additionally, through a design of experiments (DOE), it was possible to perceive the influence of some instrumental parameters of GC-MS, such as temperature, pressure intensity, and pressure pulse time in the injector on the detectability of the investigated analytes. This study allowed a satisfactory separation of the analytes and an average increase in their areas of up to $35 \%$. These aspects made it possible to obtain an analytical method with limits for the

Cite: Hara, E. L. Y.; Soares, B. G. S.; dos Santos, A. L. P.; da Silva, B. J. G.; Abate, G.; Machado, K. C.; Cestaro, B. I.; Dolatto, R. G.; Grassi, M. T. Emerging Contaminants in Aqueous Matrices Determined by Gas Chromatography-Mass Spectrometry. Braz. J. Anal. Chem., 2021, 8 (31), pp 103-116. doi: http://dx.doi.org/10.30744/brjac.2179-3425.AR-08-2021 
detection and quantification of EC between 0.03-11.00 $\mathrm{ng} \mathrm{mL}^{-1}$ and 0.10-33.35 $\mathrm{ng} \mathrm{mL}^{-1}$, respectively, and uncertainties below $9 \%$. The developed method was applied in the determination of the analytes in coastal seawater and the determined concentrations varied from $0.24 \mathrm{ng} \mathrm{L}^{-1}$ for estriol and $43.60 \mathrm{ng} \mathrm{L}^{-1}$ for cholesterol. Thus, the improvement of the silylation reaction, combined with the strategy of instrumental optimization, proved to be simple, efficient, and fast, as well as being a comparable alternative to liquid chromatography.

Keywords: Design of experiments, Chromatographic analysis, Derivatization, Surface water, Sample preparation.

\section{INTRODUCTION}

For more than two decades, compounds known as EC have attracted the attention of society, researchers, and environmental agencies. This is due to the significant persistence in the environment and the ability to disturb the biota's physiology, in addition to these substances being associated with bioaccumulation and biomagnification processes in the food chain [1,2]. Currently, approximately 700 compounds are classified as EC, are subdivided into the following classes: drugs, steroids and hormones, personal care products, surfactants, flame retardants, agricultural inputs, and industrial additives [3-5]. Although these products are essential for maintaining the lifestyle of today's society, the widespread use, inadequate disposal, and sanitary deficiencies cause them to occur in the environmental compartments, that is, in the air, in the soil, and in particular water [6-9].

In aquatic systems such as raw and treated sewage, surface water, groundwater, and water for public supply, the concentrations of EC reported in the literature can vary from $\mathrm{pg} / \mathrm{L}$ to $\mu \mathrm{g} / \mathrm{L}$ [10]. Due to the low concentrations at which they are detected and the complexity of the analysis, several extraction strategies are used for this purpose. Among them, liquid-liquid extraction (LLE) [11] and solid-phase extraction (SPE) [12], miniaturized strategies such as solid-phase microextraction (SPME), sorting by rotating disk (RDSE) [13] and passive sampling to assess bioavailability via polar organic chemical integrative sampler (POCIS) [14]. For the simultaneous quantification of several classes of EC, instrumental techniques, such as liquid phase (LC) [15-18] and gas phase (GC) chromatography, both hyphenated with mass spectrometers are the most used. However, the physical-chemical characteristics of the compounds, such as water solubility, polarity, boiling points, high molar masses, and low volatility [19] favor the use of LC in reverse phase [20] compared to GC. Additionally, GC determination requires a derivatization step that increases the length of the procedure, or the majority may not be suitable for all target compounds [21].

Although derivatization is an additional step in the analysis, the use of GC-MS can be interesting, due to the lower cost of equipment for implantation in routine laboratories and lower solvent consumption compared to the elution used in LC-MS $[13,22]$. In this sense, the literature provides some examples of how GC can be successfully used to determine EC. In a Brazilian metropolis, tap water samples were analyzed to determine 11 compounds classified as EC (caffeine, bisphenol A, 4-octylphenol, 4-nonylphenol, cholesterol, estrone, 17 $\beta$-estradiol, 17a-ethinylestradiol, progesterone, coprostanol, and stigmasterol). The extraction was performed via SPE and determination by GC-MS, being possible to quantify in the samples stigmasterol $\left(0.34 \pm 0.13 \mu \mathrm{g} \mathrm{L}^{-1}\right)$, cholesterol $\left(0.27 \pm 0.07 \mu \mathrm{g} \mathrm{L}^{-1}\right)$, caffeine $\left(0.22 \pm 0.06 \mu \mathrm{g} \mathrm{L}^{-1}\right)$, and bisphenol $A\left(0.16 \pm 0.03 \mu \mathrm{g} \mathrm{L}{ }^{-1}\right)[21]$.

In another study, the persistence, mobility, and bioavailability of 32 different types of EC were investigated at a sewage treatment plant that empties into a lake in Sweden [14]. The compounds were selected to contemplate a wide range of hydrophobicity (biocides, fragrances, organophosphates, plasticizers, surfactants, polycyclic aromatic hydrocarbons, food additives, rubbers, and polymers). In Germany, an analytical protocol was developed to determine polycyclic aromatic hydrocarbons (PAHs), polychlorinated biphenyls (PCBs), phthalate esters, nonylphenols, bisphenol A and selected steroid hormones in various types of aqueous samples such as snow and wastewater [23]. In both studies, the polar compounds were 
evaluated after a derivatization step, by silylation reaction, using the derivative BSTFA, which is widely cited for this purpose [22,24,25].

Derivatization consists of the chemical modification of the analytes to obtain products with characteristics compatible with the technique used for quantification. For EC, which has chemical groups with a polar character such as carboxylic acids, thiols, hydroxyls, amines, amides, aldehydes, and enolizable ketones, derivatization becomes mandatory for the viability of using GC-MS [26].

Based on this strategy, extraction from aqueous matrices and determination by GC-MS of 16 EC including parabens, hormones, anti-inflammatories, triclosan, and bisphenol was studied by Arismendi et al. [27]. Through the design of experiment (DOE) and response surface methodology (RSM), the authors optimized the analyte silylation. The best conditions established were the volume of the derivatizing agent (MTSFA) of $70 \mu \mathrm{L}$, the temperature at $80^{\circ} \mathrm{C}$, and a reaction time of $35 \mathrm{~min}$. Although this study reached attractive LOD values $\left(0.02-0.16 \mu \mathrm{g} \mathrm{L}^{-1}\right)$, the derivatization reaction time is still long, probably due to the low efficiency for the solution to reach thermal equilibrium with a heating plate. To overcome this limitation, some studies suggest the use of microwave irradiation to improve the efficiency of heating the reaction medium [28]. However, this strategy has not yet been applied to EC derivatization for determination by GC-MS.

Because of this, the main objective of this work was to establish a derivatization protocol for EC aiming at the determination of EC in aqueous matrices, assisted by microwaves, aiming to prioritize the increase of sensitivity and analytical frequency, concomitantly with the reduction of time and energy consumption. Besides, a chromatographic method was evaluated using DOE seeking the optimization of instrumental parameters of the GC-MS. For this purpose, the parameters injector temperature, time, and pressure pulse intensity were studied employing factorial design $\left(2^{3}\right)$ and by response surfaces methodology. Finally, the developed protocol was applied to determine the target compounds in samples of coastal seawater.

\section{MATERIALS AND METHODS}

\section{Reagents, solvents, and analytical standards}

All solvents used (methanol, chloroform, ethyl acetate, acetonitrile, dichloromethane, acetone, and hexane) were purchased from brands such as JT Baker (USA), Merck (Germany), Panreac (Spain), and the like, always with high purity or degree HPLC. The water used in the experiments was obtained via reverse osmosis in a Permution system, model RO 510 (Brazil) and then, in a Merck Millipore model Simplicity (Germany) purifier. The compounds investigated in this work were estriol, $17-\beta$-estradiol, estrone, ibuprofen, 4-octylphenol, 4-nonylphenol, triclosan, bisphenol-A, cholesterol, coprostanol, and diclofenac.

In addition to these, bisphenol-A-D16, ibuprofen-D3, and 17- $\beta$-estradiol-D3 were used as internal deuterated (IS) standards. All analytical standards and IS were purchased in individual flasks, with purity greater than $95 \%$ and supplied by Sigma-Aldrich (Germany), as well as the derivatizing N, O-Bis (trimethylsilyl) trifluoroacetamide with trimethyltrichlorosilane (BSTFA-TMCS 99:1 v/v).

\section{Derivatization of emerging contaminants}

Two procedures were evaluated to compare the efficiency of the analyte derivatization. In both, the addition of $1.0 \mathrm{~mL}$ of working solution in a concentration of $1.0 \mathrm{ng} \mathrm{mL}-1$ in a $2.0 \mathrm{~mL}$ vial was carried out. All methanol (solvent in which the analytes were prepared) was evaporated on a Christ vacuum rotary evaporator (model RVC 2-18 CD, Germany) at $60{ }^{\circ} \mathrm{C}$ for approximately $10 \mathrm{~min}$. After the solvent was completely dried, $20 \mu \mathrm{L}$ of BSTFA-TMCS was added.

In the first protocol, the vial was sealed and heated in the GC-MS oven at $70{ }^{\circ} \mathrm{C}$ for $5 \mathrm{~min}$, and in another, the vial was heated for $30 \mathrm{~min}(\mathrm{n}=3)$. After heating, the vial was removed from the oven, allowed to cool, and its content was suspended in $1.0 \mathrm{~mL}$ of hexane and the solution was injected into the GC-MS. In the second method, the vial was sealed, and the derivatization reaction was carried out in a domestic microwave oven, operated at a power of $840 \mathrm{~W}$, for $5 \mathrm{~min}$. At the end of this step, the vials were removed from the microwave oven and when they reached room temperature, the volume was made up to $1.0 \mathrm{~mL}$ with hexane and injected into the GC-MS ( $n=3)$. 


\section{Chromatographic method}

The selection of the initial instrumental parameters was performed in a GC-MS Shimadzu, model TQ8040 (Japan) equipped with automatic sampler Shimadzu, model Palm AOC-5000 Plus (Japan). All injections in the $\mathrm{GC}$ were performed in a volume of $1.0 \mu \mathrm{L}$. The injector was operated at $300{ }^{\circ} \mathrm{C}$ in splitless mode and the chromatographic column was an Agilent, model DB-5ms (USA): $30 \mathrm{~m}$ long, $0.25 \mathrm{~mm}$ thick, and internally coated with a $0.25 \mu \mathrm{m}$ thick film containing $5 \%$ phenyl and $95 \%$ dimethyl-polysiloxane. As carrier gas, helium with $99.999 \%$ purity and flow rate of $1.0 \mathrm{~mL} / \mathrm{min}$ was supplied by the company White Martins (Brazil). Three chromatographic column heating programs $(n=3)$ were evaluated, as shown in Table I.

Table I. Heating programs evaluated in the GC

\begin{tabular}{|c|c|c|c|c|c|c|c|c|}
\hline \multicolumn{3}{|l|}{ Program 1} & \multicolumn{3}{|l|}{ Program 2} & \multicolumn{3}{|l|}{ Program 3} \\
\hline Ratio ( $\left.{ }^{\circ} \mathrm{C} / \mathrm{min}\right)$ & $\mathrm{T}\left({ }^{\circ} \mathrm{C}\right)$ & $t(\min )$ & Ratio $\left({ }^{\circ} \mathrm{C} / \mathrm{min}\right)$ & $\mathrm{T}\left({ }^{\circ} \mathrm{C}\right)$ & $t$ (min) & Ratio ( $\left.{ }^{\circ} \mathrm{C} / \mathrm{min}\right)$ & $\mathrm{T}\left({ }^{\circ} \mathrm{C}\right)$ & $t(\min )$ \\
\hline- & 100 & 2 & - & 100 & 2 & - & 100 & 2 \\
\hline 12 & 310 & 3 & 15 & 160 & 2 & 10 & 310 & 7 \\
\hline \multicolumn{3}{|c|}{ Run time: $22.5 \mathrm{~min}$} & 10 & 210 & 0 & \multicolumn{3}{|c|}{ Run time: $30 \mathrm{~min}$} \\
\hline & & & 15 & 280 & 0 & & & \\
\hline & & & 10 & 300 & 1 & & & \\
\hline & & & 15 & 320 & 4 & & & \\
\hline & & & \multicolumn{3}{|c|}{ Run time: $26 \mathrm{~min}$} & & & \\
\hline
\end{tabular}

The mass spectrometer was operated in the 50 to $500 \mathrm{~m} / \mathrm{z}$ full scan mode (electron ionization, $70 \mathrm{eV}$ ) and the mass analyzer is a quadrupole type. The transfer line and the ion source remained at a constant temperature at $300^{\circ} \mathrm{C}$ and $250{ }^{\circ} \mathrm{C}$, respectively.

\section{Optimization of instrumental parameters of GC-MS}

To increase the detectability of the compounds, through the investigation of adjustments of the instrumental parameters of the GC-MS, a DOE was carried out considering three factors studied at two levels $\left(2^{3}\right)$, in addition to 1 central point $(n=2)$, totaling 18 experiments. For that, the parameters of the previous section (chromatographic method) were maintained, and the variables investigated were injector temperature (1), duration of the application of the pressure pulse in the injector (2), and the intensity of the pressure pulse (3), as shown in Table II.

Table II. Instrumental parameters of the GC-MS investigated in factor design $2^{3}$

\begin{tabular}{llccc}
\hline & & \multicolumn{3}{c}{ Level } \\
\cline { 3 - 5 } & Parameters & $(-)$ & $\mathbf{0}$ & $(+)$ \\
\hline 1 & Injector $\mathrm{T}\left({ }^{\circ} \mathrm{C}\right)$ & 200 & 250 & 300 \\
2 & Pressure pulse time $(\mathrm{min})$ & 1 & 3 & 5 \\
3 & Pressure pulse $(\mathrm{kPa})$ & 10 & 80 & 150 \\
\hline
\end{tabular}




\section{Quality Assurance (QA) and Quality Control (QC)}

The analytical curves were obtained using the linear regression method, from the correlation between the concentration of each analyte, versus the ratio values between the peak area of the analyte and the internal standard. The analytical curves were prepared at seven concentration levels: $5,10,20,40,80$, 120 and $160 \mathrm{ng} \mathrm{mL}^{-1}(\mathrm{n}=3)$. The IS concentration, bisphenol-A-D16, ibuprofen-D3, and 17- $\beta$-estradiol-D3, was kept constant at $100 \mathrm{ng} \mathrm{mL}^{-1}$. The preparation and injection of the solutions were carried out daily to minimize the effects of solvent and analyte volatilization.

The limits of detection (LOD) and quantification (LOQ) were calculated based on the merit parameters of the analytical curves, obtained in triplicate, from the equations $L O D=3.3\left(s S^{-1}\right)$ and $L O Q=10\left(s S^{-1}\right)$. Where " $s$ " corresponds to the standard deviation estimate of the linear coefficient of the analytical curves and " $S$ " the mean value of the sensitivity or slope.

To assess repeatability, a solution containing a mixture of analytes in a concentration of $100 \mathrm{ng} \mathrm{mL}^{-1}$ was prepared and 5 injections were made on two consecutive days. After that, the RSD of the peak areas of the analytes was calculated.

The accuracy was evaluated through recovery tests, performed with $1.0 \mathrm{~L}$ of coastal seawater in amber flasks where aliquots of the solution with the mixture of the EC standards were transferred in the concentrations of $50 \mathrm{ng} \mathrm{L}^{-1}$ and $100 \mathrm{ng} \mathrm{L}^{-1}(\mathrm{n}=3)$. The flasks were manually shaken, and then solid-phase extraction (SPE) was performed. In addition, two blanks were made with sea water.

\section{Extraction of emerging contaminants from water by SPE}

EC extraction was performed using the SPE method. For this purpose, cartridges were used for extraction in solid-phase Oasis HLB (Hydrophilic/Lipophilic-Balance) purchased from Waters Co. (USA), containing $500 \mathrm{mg}$ of sorbent phase and with a capacity of $6 \mathrm{~mL}$. Then, the cartridges were connected to a manifold processing system consisting of a vacuum-resistant glass chamber [29] connected to a Tecnal oil-free vacuum pump, model TE-0581.

The extraction procedure was performed as follows: first, the sorbent phase of the cartridges was conditioned with two $3.0 \mathrm{~mL}$ aliquots of methanol, followed by two $3.0 \mathrm{~mL}$ aliquots of ultrapure water. Then, the cartridges were connected to the manifold through PTFE Sulpeco tubes, model Visiprep (USA) to allow the continuous passage of the entire sample volume $(1.0 \mathrm{~L})$ through the sorbent phase.

This system allowed us to work continuously and cleanly, since all the tubes and connections used are made of materials with a low capacity of organic compounds, thus minimizing problems of contamination and memory effect. Then, the total volume of the sample was eluted through the cartridge, under vacuum, under a controlled flow of $6 \mathrm{~mL} / \mathrm{min}$. After the end of the extraction, the cartridges were packed in aluminum foil and kept under refrigeration $\left(4^{\circ} \mathrm{C}\right)$, until elution and chromatographic determination.

The analyte elution was also performed with the aid of a manifold. Two $2.5 \mathrm{~mL}$ aliquots of methanol were added to the SPE cartridges, followed by a $2.0 \mathrm{~mL}$ aliquot of acetonitrile. The eluates were collected in $10 \mathrm{~mL}$ test tubes and taken to the rotary vacuum evaporator for complete drying of the solvents. Then, derivatization, suspension in $1.0 \mathrm{~mL}$ of hexane, and injection into the GC-MS were performed.

\section{Method application}

Seawater samples ( $n=3$ ) were collected at point S19 $56^{\prime} 43.7^{\prime \prime}$ W40 $08^{\prime} 44.2^{\prime \prime}$, located on the southeast coast of Brazil, state of Espírito Santo in the city of Aracruz, whose population is approximately 100 thousand inhabitants and the sewage system reach $80 \%$ of the population [28].

All samples were placed in $1.0 \mathrm{~L}$ amber bottles and kept refrigerated $\left(4^{\circ} \mathrm{C}\right)$ for a maximum of 7 days until they were prepared and analyzed. The analysis of the samples followed the procedure using SPE. 


\section{RESULTS AND DISCUSSION \\ Derivatization of EC}

Derivatization is a crucial procedure for the determination of EC by GC-MS [30] and in this work, the silylation reaction was used. Also, the protocol that uses the derivative BSTFA reagent, less susceptible to steric effects in larger molecules, such as hormones, was selected. The reaction consists of chemically modifying the EC structure, via a bimolecular nucleophilic substitution mechanism (SN2) [26]. The hydrogen atom present in hydroxyl and $\mathrm{EC}$-linked functional groups $(\mathrm{ECOH})$ is replaced by the radical trimethylsilyl, $\left(\mathrm{CH}_{3}\right)_{3} \mathrm{SiX}$, according to Equation 1:

$$
\mathrm{ECOH}+\mathrm{XSi}\left(\mathrm{CH}_{3}\right)_{3} \rightarrow \mathrm{ECOSi}\left(\mathrm{CH}_{3}\right)_{3}+\mathrm{HX} \quad \text { Equation } 1
$$

This gives the analytes greater volatility due to the drastic reduction in intermolecular hydrogen interactions, improved affinity for the stationary phase of the chromatographic column, and greater thermal stability. The reaction yield is favored, kinetically, and thermodynamically, by the time and adequate heating of the reaction medium [26].

Considering the balance shift in the direction of product formation it is interesting for applications in methods that precede the chromatographic determinations. In this sense, Figure 1 presents a comparative graph of the efficiency results of the derivatization performed by heating the solution containing the EC in the GC oven for 30 min and in the microwave oven for 5 min.

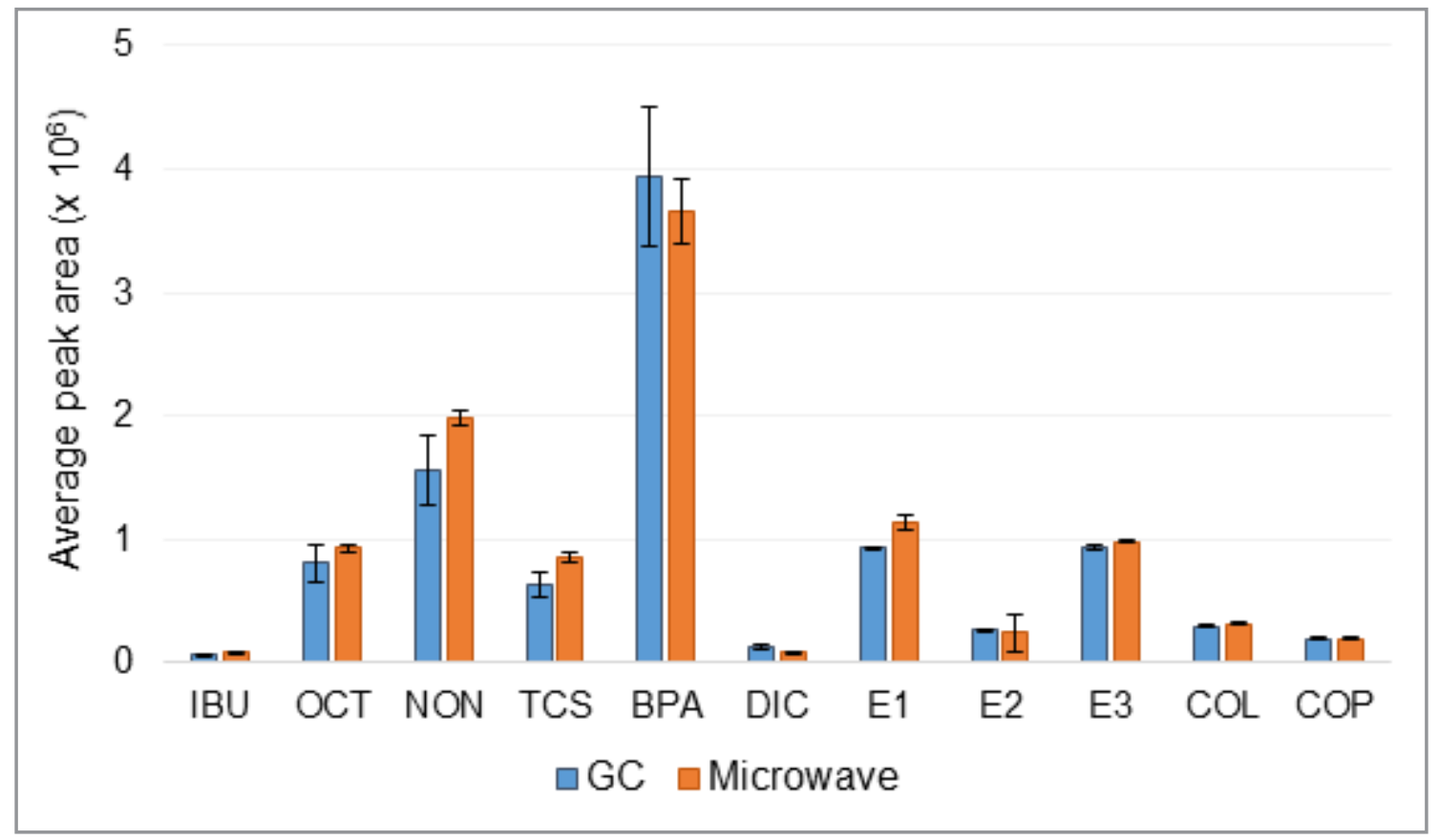

Figure 1. Comparison of the efficiency of derivatization reactions, from a solution of EC in a concentration of $1.0 \mu \mathrm{g} / \mathrm{mL}$, in the GC oven for $30 \mathrm{~min}$ and a domestic microwave oven for $5 \mathrm{~min}$ : IBU: ibuprofen; OCT: 4-octylphenol; NON: 4-nonylphenol; TCS: triclosan; BPA: bisphenol-A; DIC: diclofenac; E1: estrone; E2: 17- $\beta$-estradiol; E3: estriol; COL: cholesterol; COP: coprostanol.

Analyzing the mean values of the peak areas of the analytes in Figure 1, it is possible to verify the efficiency of the derivatization process for both the reaction in the GC oven and the domestic microwave since the values of the analyte areas are well next. However, if we take 4-nonylphenol (NON) as an example, the average peak area of the compound was $1.6 \times 10^{6} \mathrm{AU}$ in the GC oven, while for the domestic microwave the value was $2.1 \times 10^{6} \mathrm{AU}$, that is, on average there was an increase of $31 \%$. Similar behavior 
was observed for four other compounds (IBU, TCS, E1, and E3), and for the other analytes, the standard deviation estimate values (Figure 1) were statistically equal, or slightly higher, as verified for DIC.

It should be noted that another solution containing the analytes was also heated in the GC oven for $5 \mathrm{~min}$. However, the heating time was not enough to promote the derivatization reaction of the analytes, because in none of the chromatograms the peaks of the compounds were detected. Thus, this procedure was interrupted.

Probably the superior performance of the microwave is associated with the effective heating of the system containing reagents and analytes. The increase in temperature occurs in molecules that have an appropriate permanent dipole moment and absorb radiation through rotational excitation [31]. This occurs in the BSTFA-TMCS solution and to a lesser extent in the glass walls of the vials, which may contain adsorbed moisture, contributing to increasing the effectiveness of the thermal process. On the other hand, in the GC oven, more time is needed to achieve thermal equilibrium, that is, the uneven heating of the reaction medium decreased the reaction yield.

Because of obtaining higher average areas in a microwave oven, this was selected for the other stages of the work, especially due to the shorter reaction time $(5 \mathrm{~min})$ and the characteristics of this equipment, such as simplicity of operation, cost, and wide availability. Besides, the lowest time and energy expenditures were considered, aiming at the development of less energy-intensive protocols. It should be noted that in some situations the use of domestic microwave ovens in the laboratory is not recommended, especially for safety reasons [31]. On the other hand, when possible, its use requires caution and modifications are important to adapt the device for each purpose [32].

\section{GC-MS optimization}

Three temperature schedules were evaluated in the GC-MS to decrease the running time, associated with an efficient resolution of the analytes. Figure 2 shows the mean values of the analyte peak areas that were obtained from the GC heating ramps, as shown in Table I.

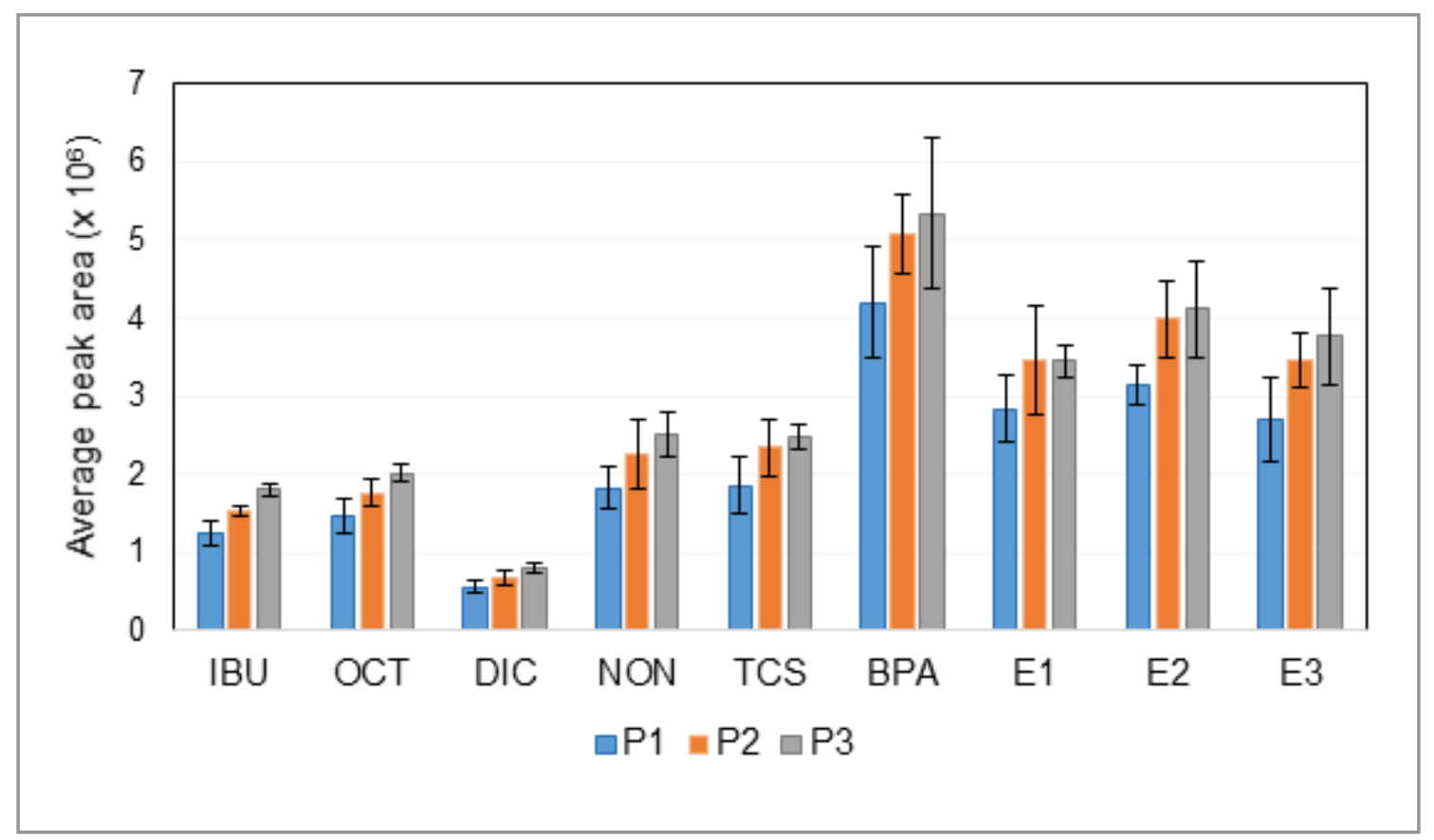

Figure 2. Mean values of the peak areas of the analytes, referring to a solution of the EC in a concentration of $1.0 \mu \mathrm{g} / \mathrm{mL}$, obtained from the GC heating programs. 
Temperature gradient 1 showed smaller peak areas, on average, compared to 2 and 3 . Comparing the three schedules, according to standard deviation estimation bars, it is possible to notice that 1-2 and 2-3 are statistically similar. Only 1-3 differ, within the limits of their standard deviation estimates.

Regarding ramp 2, the heating rate was increased from $10^{\circ} \mathrm{C} / \mathrm{min}$ to $15^{\circ} \mathrm{C} / \mathrm{min}$, aiming at the faster separation of the compounds. According to Sequinel et al. [33], for there to be gains in the quality of the separation and the speed of the analysis, the increase in the column temperature must be more expressive, combined mainly with a column of shorter length and greater flow of the carrier gas. However, the increase in the heating rate caused the chromatographic run time to decrease to 26 min, but there was no statistically significant gain in the mean values of the analyte peak areas.

On the other hand, program 3 exhibited peak areas, on average, $22 \%$ above other programs. This may be related to the lower heating rate of the column applied in program $3\left(10^{\circ} \mathrm{C} / \mathrm{min}\right)$, while in program 1 the ratio was $12^{\circ} \mathrm{C} / \mathrm{min}$. In this case, it can be considered that the decrease in the heating ratio by 3 provided an improvement in the chromatographic resolution, however, the analysis time increased, as expected [34]. For these reasons, schedule 3 was maintained for the other stages of this work.

With the preliminary instrumental conditions, it was possible to obtain the fragmentation patterns of the analytes, in terms of their mass/charge ratios $(\mathrm{m} / \mathrm{z})$. Table III presents some physical-chemical parameters of the compounds and the respective $\mathrm{m} / \mathrm{z}$ selected for quantification and confirmation. The chromatographic data were obtained through the individual injection of the solutions of each EC derivatized at a concentration of $1.0 \mu \mathrm{g} \mathrm{mL}^{-1}(\mathrm{n}=3)$.

Table III. Physico-chemical parameters and $\mathrm{m} / \mathrm{z}$ ratios used in the quantification and confirmation of EC

\begin{tabular}{llccccc}
\hline Compound & Class & $\begin{array}{c}\text { Molar mass } \\
\left(\mathbf{g ~ m o l} \mathbf{~ m}^{-1}\right)\end{array}$ & $\begin{array}{c}\text { Boiling } \\
\text { point }\left({ }^{\circ} \mathbf{C}\right)\end{array}$ & log Kow & $\begin{array}{c}\text { Quantification } \\
\text { ion }(\mathbf{m} / \mathbf{z})\end{array}$ & $\begin{array}{c}\text { Confirmation } \\
\text { ion }(\mathbf{m} / \mathbf{z})\end{array}$ \\
\hline Ibuprofen & Pharmaceutical & 206 & 319 & 4.0 & 160 & $233 ; 263$ \\
\hline 4-octylphenol & Surfactant & 206 & 315 & 5.5 & 179 & 278 \\
\hline 4-nonylphenol & Surfactant & 220 & 330 & 5.8 & 179 & 292 \\
\hline Triclosan & Personal Care & 290 & 344 & 4.8 & 200 & $346 ; 359$ \\
\hline Bisphenol A & Plasticizer & 228 & 400 & 3.3 & 357 & - \\
\hline Diclofenac & Pharmaceutical & 296 & 412 & 4.1 & 214 & $242 ; 276$ \\
\hline Estrone & Estrogen & 270 & 445 & 3.1 & 342 & $257 ; 218$ \\
\hline Estradiol & Estrogen & 272 & 445 & 4.1 & 416 & $285 ; 326$ \\
\hline Estriol & Estrogen & 288 & 469 & 2.5 & 296 & $311 ; 414$ \\
\hline Coprostanol & Sterol & 389 & 475 & 8.8 & 215 & $355 ; 445$ \\
\hline Cholesterol & Sterol & 387 & 480 & 8.7 & 329 & $369 ; 458$ \\
\hline
\end{tabular}

In the investigation of instrumental parameters of the GC-MS, splitless injections are recommended for low volume samples (between $1.0 \mu \mathrm{L}$ and $3.0 \mu \mathrm{L}$ ) and analytes whose concentrations are in the order of $\mathrm{pg} \mathrm{L}^{-1}$ to $\mu \mathrm{g} \mathrm{L}^{-1}$ [35].

Because of the low concentrations of compounds reported in the literature in natural waters, it was necessary to use the splitless injection mode and to evaluate the most appropriate temperature of the injector in order not to degrade the analytes as well as sufficiently volatilize the derivatized EC [36]. Also, another parameter evaluated was the internal pressure of the injector during sample injection. 
The pressure was applied for a while during the injection and then returned to the default value. Thus, there was an increase in the transition speed of the injector compounds to the column, which in turn led to a reduction in the band widening and the narrowing of the EC peaks [37].

Considering these aspects, it is important to note that the 18 experiments were carried out randomly and that for each experiment, a solution containing the mixture of the analytes was prepared. From the integration of the peak areas of each contaminant and the mathematical treatment proposed by the geometric mean of the areas, it was possible to analyze the effects of each parameter.

Thus, Figures $3 \mathrm{~A}$ and $3 \mathrm{~B}$ make the interpretation of the results intelligible. In Figure $3 \mathrm{~A}$, the response surfaces referring to the time of application of pressure in the injector versus the temperature of the injector, and the pressure applied in the injector versus the injector T are shown.
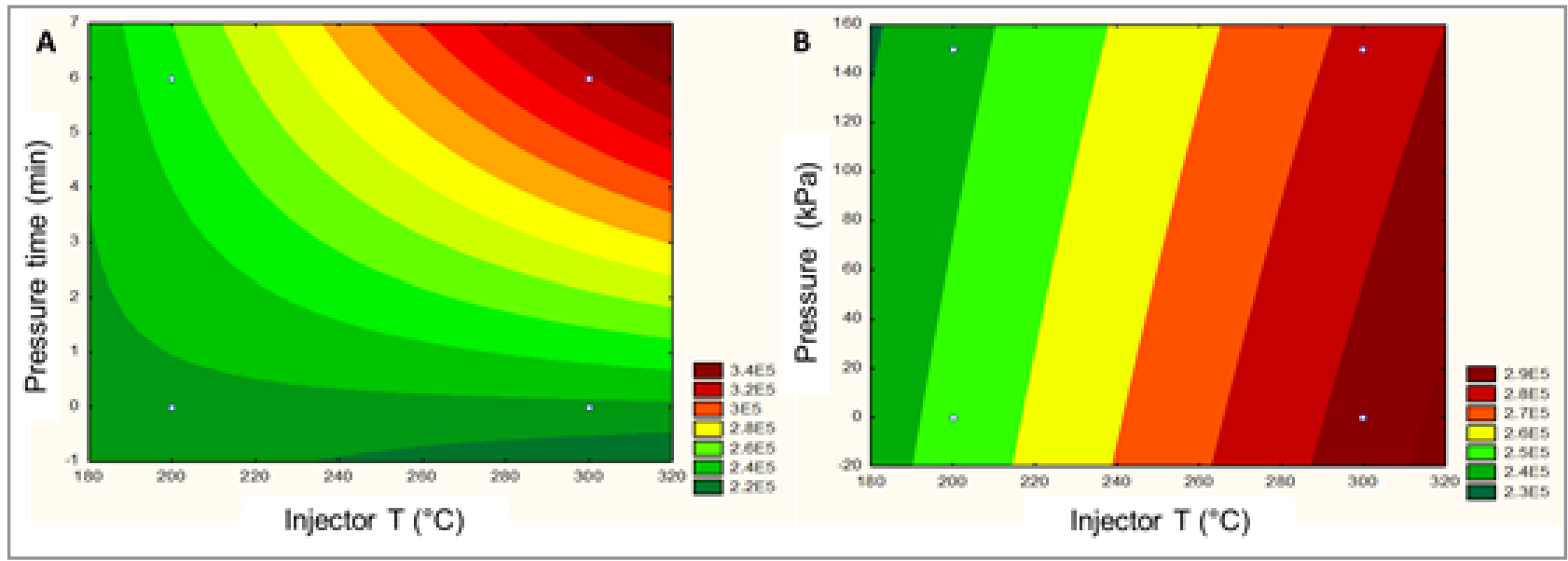

Figure 3. Response surfaces regarding the combination of pressure time versus injector temperature $(A)$ and pressure versus injector temperature $(B)$.

The more intense red colors indicate the parameters that can provide greater gains in responses, as observed in the abscissa where the injector temperature $\left(>280^{\circ} \mathrm{C}\right)$ is represented. In the ordinates, the intensity of the applied pressure is represented.

In Figure 3B, it is possible to notice that the lower pressures $(<80 \mathrm{kPa})$ coincide with the more intense shades in red. Thus, it was decided to use a temperature of $300{ }^{\circ} \mathrm{C}$ and $80 \mathrm{kPa}$ in the other stages of the work. In Figure 3A, it is possible to observe the response surface regarding the effect of the injector temperature with the time of application of the pressure pulse.

In the same way, it appears that the red colors are more intense and correspond to both the longest application times of the pressure pulse (> $5 \mathrm{~min}$ ) and the highest temperatures. For the remaining stages of this work, we chose to use $7 \mathrm{~min}$. To investigate the significance of the effects and possible interactions between the variables, the results were evaluated using the Pareto diagram, shown in Figure 4.

Figure 4 shows a Pareto chart that corroborates the results presented in Figures $3 \mathrm{~A}$ and $3 \mathrm{~B}$. Thus, considering minimum Student's $t$ values or tc $=2.31$ and at a $95 \%$ confidence level, the effects of "pressure application time", injector temperature, and pressure intensity are significant, that is, the optimization of these parameters can change the detectability of the compounds positively. 


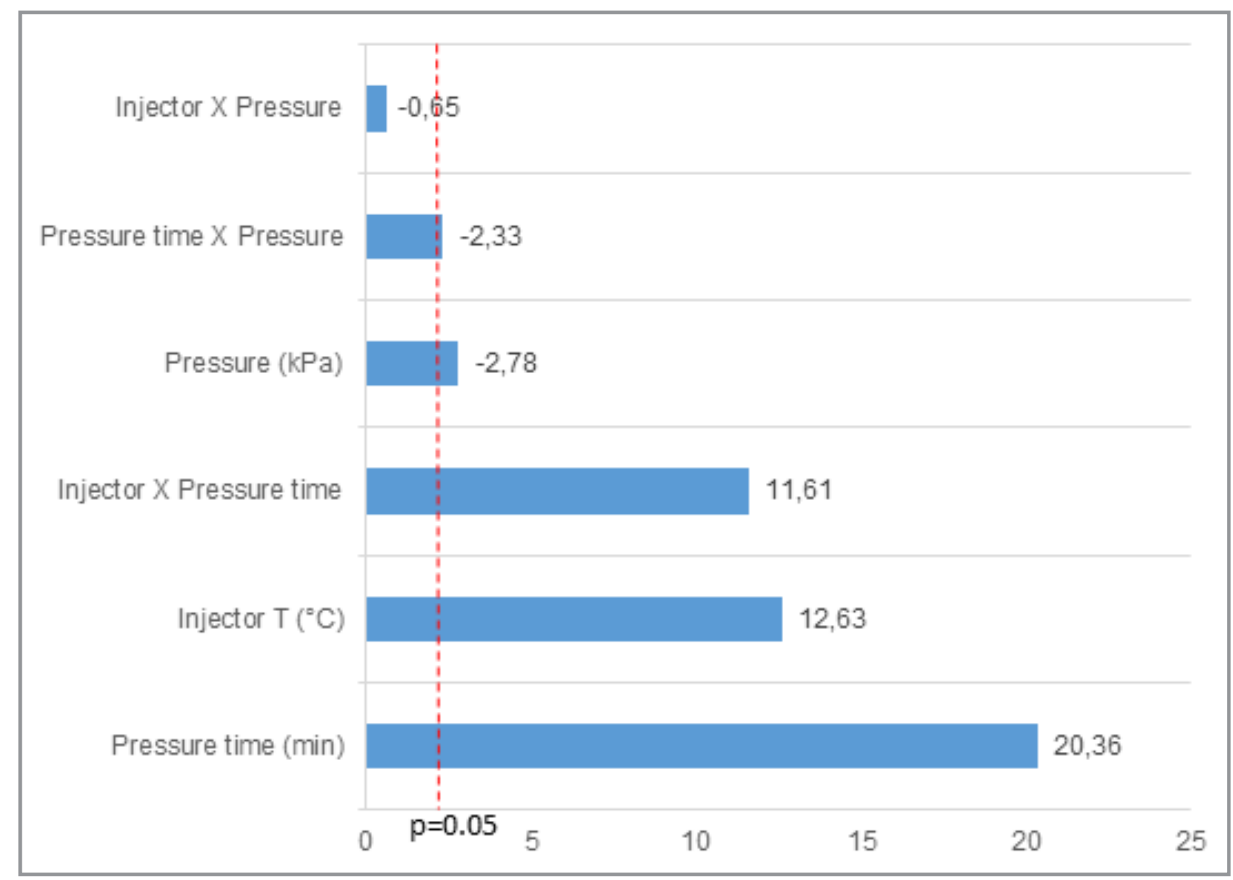

Figure 4. Pareto chart presents the effects of the parameters of the design of experiments.

Likewise, it can be inferred that the application of the pressure pulse for a longer period, associated with a higher injector temperature, enabled an increase in the peak areas of the analytes.

This is evident since both effects are much higher than the tc value. Besides, an interaction between these two factors was verified, favoring the volatilization efficiency of the compounds and the transfer of masses to the chromatographic column. Although the pressure intensity does not show significant significance, it can be considered that the intermediate values of pressure intensity are sufficient for adequate separation of the analytes.

The optimization of the instrumental parameters of the GC-MS with the aid of the DOE $2^{3}$, enabled gains in the areas of the EC peaks between 15\% (DIC) to 35\% (NON). Thus, this increase in the sensitivity of the instrumental technique is crucial in determining the compounds since they are present in the environment, typically in the order of $\mathrm{ng} / \mathrm{L}$.

\section{QA/QC}

Table IV presents the values of the coefficients of determination, detection limit, and limit of quantification.

Table IV. Determination coefficients $\left(R^{2}\right)$ And instrumental LOD and LOQ values

\begin{tabular}{cccccccccccc}
\hline & IBU & OCT & NON & TCS & BPA & DIC & E1 & E2 & E3 & COP & COL \\
\hline $\mathbf{R}^{2}$ & 0.9991 & 0.9994 & 0.9990 & 0.9990 & 0.9995 & 0.9993 & 0.9960 & 0.9999 & 0.9989 & 0.9996 & 0.9963 \\
$\begin{array}{c}\text { LOD } \\
\mathbf{n g ~ m L}\end{array}$ & 2.40 & 0.51 & 1.16 & 1.33 & 1.33 & 11.00 & 0.03 & 0.15 & 0.16 & 0.11 & 0.11 \\
$\begin{array}{c}\text { LOQ } \\
\mathbf{n g ~ m L}\end{array}$ & 7.23 & 1.55 & 3.53 & 4.04 & 4.02 & 33.35 & 0.10 & 0.45 & 0.48 & 0.35 & 0.35 \\
\hline
\end{tabular}

IBU: ibuprofen; OCT: 4-octylphenol; NON: 4-nonylphenol; TCS: triclosan; BPA: bisphenol-A; DIC: diclofenac; E1: estrone; E2: 17- $\beta$-estradiol; E3: estriol. 
The value of $\mathrm{R}^{2}$ allows estimating the linearity of the analytical curve, because the closer to 1.0 , the smaller the dispersion of the set of experimental points and the lower the uncertainty of the determination coefficients $[38,39]$. Thus, it was possible to conclude that the values presented in Table IV are satisfactory and meet the requirements established in the literature.

Based on this, analytical curves were obtained in triplicates and their parameters (intercept and slope) used to evaluate the performance of the protocol.

The values of the limits of detection and quantification were considered satisfactory considering that a GC-MS was used and thus requires a previous derivatization step to determine such values. Despite this, the values are comparable to those in the literature even when an LC-MS [40-42] and GC-MS [13] were used.

Repeatability represents the agreement between the results of successive measurements of the same method performed under the same measurement conditions. Thus, the analyst, the preparation of the standard solutions, the injections, and the equipment were maintained throughout the work. Figure 5 shows the graph of the results regarding repeatability. In this procedure, in total, 10 injections were performed from a single vial.

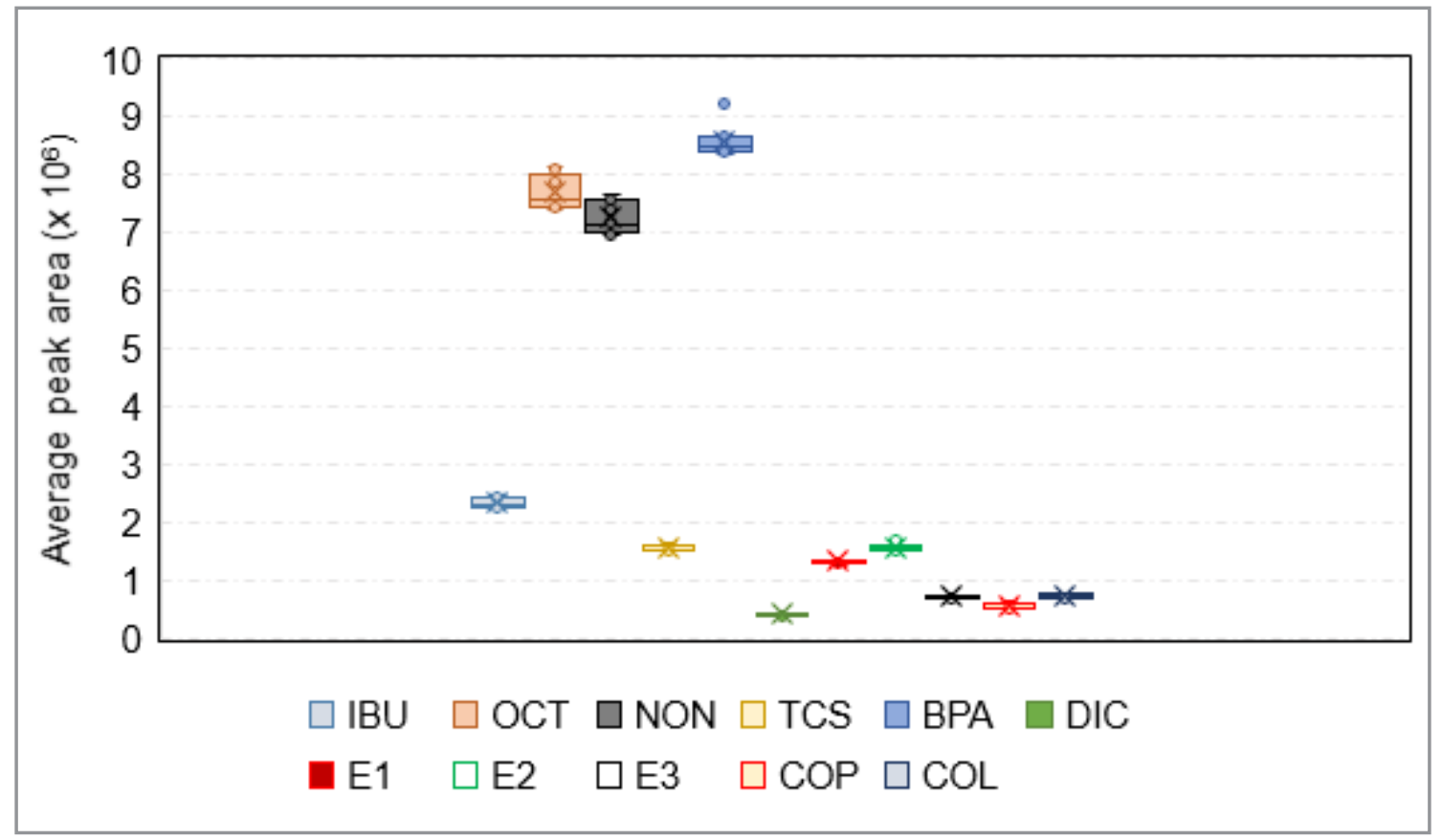

Figure 5. Distribution of analytes against repeatability: IBU: ibuprofen; OCT: 4-octylphenol; NON: 4-nonylphenol; TCS: triclosan; BPA: bisphenol-A; DIC: diclofenac; E1: estrone; E2: 17- $\beta$-estradiol; E3: estriol; COP: coprostanol; COL: cholesterol.

The results show a satisfactory resolution of the analytes as well as a reduced variability in the peak area values of each analyte. The RSD values varied between $3 \%$ and $9 \%$. In this sense, it was possible to conclude that the procedure was satisfactory due to the low variability of peak area values.

In order to carry out a systematic and more relevant study from an analytical point of view, we chose to carry out a recovery study using coastal seawater. From an environmental perspective, the analysis of this matrix is even more significant in a country like Brazil that has a major deficiency in sewage treatment. It is important to note that almost $27 \%$ of the Brazilian population lives close to the coast, that is, there are more than 50 million people who have their tailings thrown in the Atlantic, mostly without any type of treatment [43]. 
The recovery study for the seawater sample fortified with $50 \mathrm{ng} \mathrm{\textrm {L } ^ { - 1 }}$ showed values between $56 \%$ and $142 \%$ for estriol, cholesterol, triclosan, estradiol and estrone with RSD $<20 \%$. Ibuprofen, octylphenol and nonylphenol showed recovery between $18 \%$ and $22 \%$ with RSD $<5 \%$. For the study with seawater fortified with $100 \mathrm{ng} \mathrm{L}^{-1}$, the recovery varied between $53 \%$ and $166 \%$ for cholesterol, estriol, triclosan, estradiol, estrone. The RSD was less than $31 \%$. Ibuprofen and octylphenol would vary between $16 \%$ and $21 \%$. In the analysis of the blanks with seawater, the concentrations of the analytes were lower than the LOD for all emerging contaminants.

\section{Method application}

The optimized protocol was applied to surface water samples to assess its applicability. Figure 6 presents the results for the quantification of EC in seawater samples.

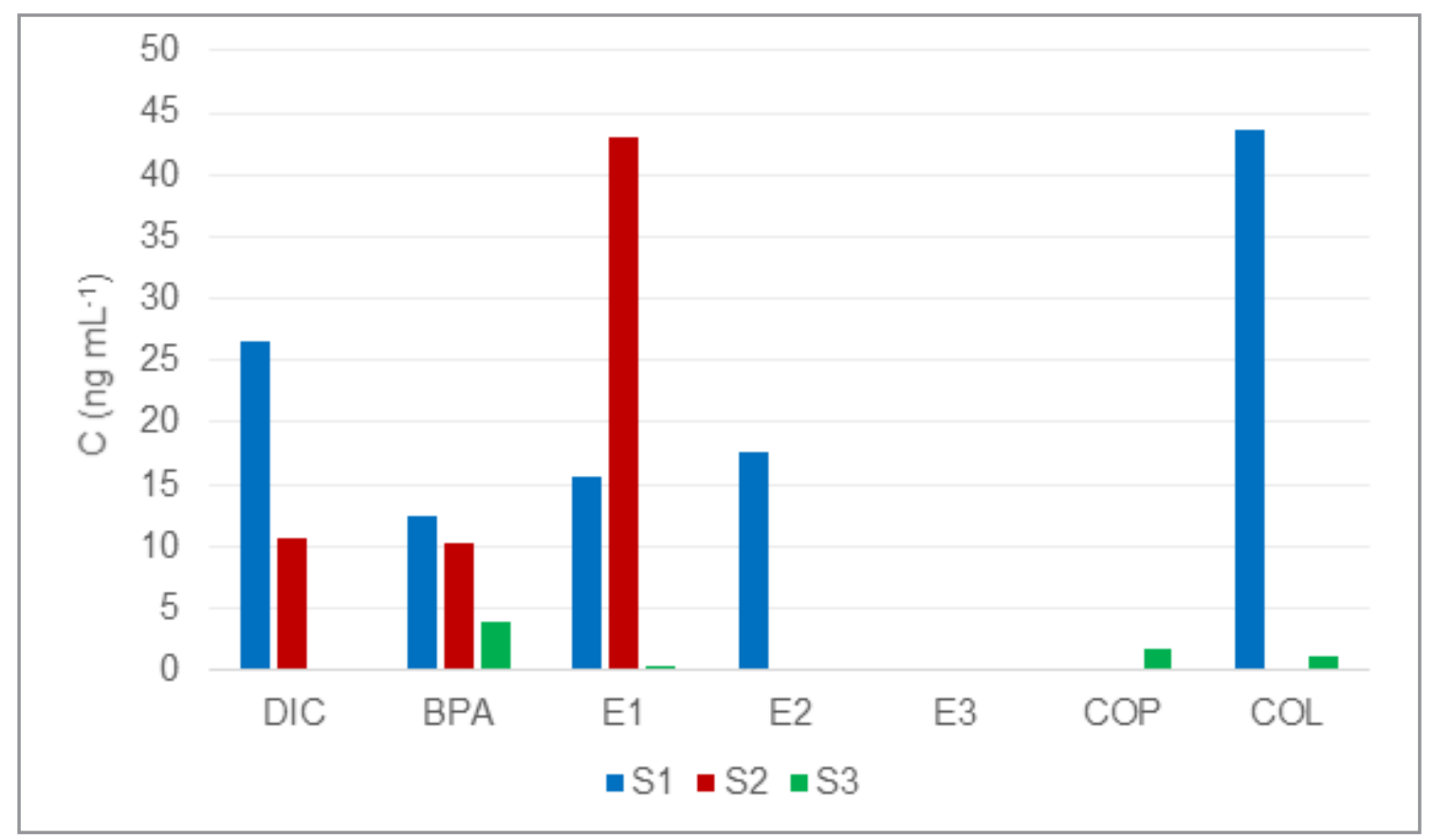

Figure 6. EC concentrations determined in seawater samples.

The chromatographic analytical method developed together with SPE enabled the determination of seven analytes in the sample: DIC (11-27 ng mL-1), BPA (4-13 $\left.\mathrm{ng} \mathrm{mL}^{-1}\right), \mathrm{E} 1$ (0.9-43 $\left.\mathrm{ng} \mathrm{mL}^{-1}\right)$, E2 (17 ng $\left.\mathrm{mL}^{-1}\right)$, E3 $\left(0.50 \mathrm{ng} \mathrm{mL}^{-1}\right), \mathrm{COP}\left(2 \mathrm{ng} \mathrm{mL}^{-1}\right)$ and COL $\left(2-43 \mathrm{ng} \mathrm{mL}^{-1}\right)$. Although the sampling site belongs to an environmental protection area, it is deficient in basic sanitation.

Approximately $80 \%$ of the region is served by a sewage network. Considering this fact, the presence of hormones and sterols, which are markers of sewage contamination, may be indicative of the region's sanitary deficiency [44]. Values are close to those reported by [43] in marine waters and with high salinity, determined by LC-MS/MS: BPA (0.19-0.49 ng mL-1), DIC (<0.47-79.89 ng mL-1), E1 (<0.56-1.95 ng mL-1), and E2 $\left(<5.28-31.43 \mathrm{ng} \mathrm{mL}^{-1}\right)$, except BPA and E1. In this sense, complementary studies involving spatial and temporal sampling in this region can be performed using the procedure developed here for a detailed environmental assessment.

\section{CONCLUSION}

The derivatization step was improved and provided less reaction time, which favored an increase in the analytical frequency. Besides, this has been achieved by employing a low-cost and widely available household microwave device. 
Also, the multivariate optimization of instrumental parameters of the GC-MS technique, generally neglected in the literature, provided a significant improvement in terms of analyte sensitivity. This was verified after the application of the method in the seawater samples, revealing the presence of the analytes in trace concentrations, compatible with those reported in the literature.

Because of these aspects, it is possible to conclude that the analytical strategies used in this work can be classified as simple, low cost, and obtained with a reduced number of experiments. This suggests that the steps reported here are not limited to EC but can be extended to the determination of other classes of compounds or other instrumental techniques, mainly, in the aspect that involves exploring the full potential of the equipment.

\section{Conflicts of interest}

There are no conflicts to declare.

\section{Acknowledgements}

The authors are grateful to "Instituto Nacional de Ciências e Tecnologias Analíticas Avançadas" (INCTAA, proc. 573894/2008-6 and 465768/2014-8), "Financiadora de Estudos e Projetos" (FINEP, CTHIDRO 01/2013) and "Conselho Nacional de Desenvolvimento Científico e Tecnológico" (CNPq) for the financial support. This study was financed in part by the "Coordenação de Aperfeiçoamento de Pessoal de Nível Superior" - Brazil (CAPES) - Finance Code 001.

\section{REFERENCES}

1. Celano, R.; Piccinelli, A. L.; Campone, L.; Rastrelli, L. J. Chromatogr. A, 2014, 1355, pp 26-35 (http:// dx.doi.org/10.1016/j.chroma.2014.06.009).

2. Barbosa, M. O.; Moreira, N. F. F.; Ribeiro, A. R.; Pereira, M. F. R.; Silva, A. M. T. Water Research, 2016, 94, pp 257-79 (https://doi.org/10.1016/j.watres.2016.02.047).

3. European Parliament. Directive 2013/39/EU. Priority substances in the field of water policy. Official Journal of the European Union, 2013. Available at: https://eur-lex.europa.eu/LexUriServ/LexUriServ. do?uri=OJ:L:2013:226:0001:0017:EN:PDF [Accessed 10 January 2021].

4. Farré, M.; Petrovic, M.; Gros, M.; Kosjek, T.; Martinez, E.; Heath, E.; Osvald, P.; Loos. R.; Le Menach, K.; Budzinski, H.; et al. Talanta, 2008, 76 (3), pp 580-90.

5. Vorkamp, K.; Bossi, R.; Bester, K.; Bollmann, U. E.; Boutrup, S. Sci. Total Environ., 2014, 470-471, pp 459-68 (http://dx.doi.org/10.1016/j.scitotenv.2013.09.096).

6. Richardson, S. D.; Kimura, S. Y. Environ. Technol. Innov., 2017, 8, pp 40-56.

7. Martín-Pozo, L.; de Alarcón-Gómez, B.; Rodríguez-Gómez, R.; García-Córcoles, M. T.; Çipa, M.; ZafraGómez, A. Talanta, 2019, 192, pp 508-533 (https://doi.org/10.1016/j.talanta.2018.09.056).

8. Zenobio, J. E.; Sanchez, B. C.; Leet, J. K.; Archuleta, L. C.; Sepúlveda, M. S. Chemosphere, 2015, 120, pp 750-755.

9. Albero, B.; Sánchez-Brunete, C.; García-Valcárcel, A. I.; Pérez, R. A.; Tadeo, J. L. TrAC - Trends Anal. Chem., 2015, 71, pp 110-118 (http://dx.doi.org/10.1016/j.trac.2015.03.015).

10. Montagner, C. C.; Vidal, C.; Acayaba, R. D. Quim. Nova, 2017, 40 (9), pp 1094-1100.

11. Vashisht, D.; Kumar, A.; Mehta, S. K.; Ibhadon, A. Environmental Advances, 2020, 1, 100002 (https:// doi.org/10.1016/j.envadv.2020.100002).

12. Sodré, F. F.; Locatelli, M. A. F.; Jardim, W. F. Water Air Soil Pollut., 2010, 206 (1-4), pp 57-67.

13. Arismendi, D.; Becerra-Herrera, M.; Cerrato, I.; Richter, P. Talanta, 2019, 201, pp 480-489 (https://doi. org/10.1016/j.talanta.2019.03.120).

14. Blum, K. M.; Andersson, P. L.; Ahrens, L.; Wiberg, K.; Haglund, P. Sci. Total Environ., 2018, 612, pp 1532-42 (https://doi.org/10.1016/j.scitotenv.2017.09.006).

15. Acir, I. H.; Guenther, K. Sci. Total Environ., 2018, 635, pp 1530-1546.

16. Bergman, A.; Heindel, J.; Jobling, S.; Kidd, K.; Zoeller, R. T. Toxicol Lett., 2012, 211:S3. 
17. Kiguchi, O.; Sato, G.; Kobayashi, T. Environ. Sci. Pollut. Res., 2016, 23 (22), pp 22513-29.

18. Fantuzzi, G.; Aggazzotti, G.; Righi, E.; Predieri, G.; Castiglioni, S.; Riva, F.; Zuccato. E. Sci. Total Environ., 2018, 635, pp 956-963 (https://doi.org/10.1016/j.scitotenv.2018.04.155).

19. Köck-Schulmeyer, M.; Postigo, C.; Farré, M.; Barceló, D.; López de Alda, M. Chemosphere, 2019, 215, pp 515-523.

20. Rodríguez, I.; Quintana, J. B.; Carpinteiro, J.; Carro, A. M.; Lorenzo, R. A.; Cela, R. J. Chromatogr. A, 2003, 985 (1-2), pp 265-74.

21. Sodré, F. F.; Locatelli, M. A. F.; Jardim, W. F. Water Air Soil Pollut., 2010, 206 (1-4), pp 57-67.

22. Prazeres, E. S.; dos Santos, M. B.; Barreto, A. de A.; Coutinho, J. P.; da Silva, E. G. P.; Melo, S. C. O.; de Jesus, R. M.; Lôbo, I. P. Microchem. J., 2021, 161 (https://doi.org/10.1016/j.microc.2020.105785).

23. Prieto, A.; Schrader, S.; Moeder, M. J. Chromatogr. A, 2010,1217 (38) pp 6002-6011.

24. Caban, M.; Czerwicka, M.; Łukaszewicz, P.; Migowska, N.; Stepnowski, P.; Kwiatkowski, M.; Kumirska, J. J. Chromatogr. A, 2013, 1301, pp 215-224 (http://dx.doi.org/10.1016/j.chroma.2013.05.073).

25. Román, I. P.; Chisvert, A. A.; Canals, A. J. Chromatogr. A, 2011, 1218 (18), pp 2467-75.

26. Schummer, C.; Delhomme, O.; Appenzeller, B. M. R.; Wennig, R.; Millet, M. Talanta, 2009, 77 (4), pp 1473-82.

27. Arismendi, D.; Becerra-Herrera, M.; Cerrato, I.; Richter, P. Talanta, 2019, 201, pp 480-489 (https://doi. org/10.1016/j.talanta.2019.03.120).

28. Chu, T. Y.; Chang, C. H.; Liao, Y. C.; Chen, Y. C. Talanta, 2001, 54 (6), pp 1163-1171.

29. Machado, K. C.; Grassi, M. T.; Vidal, C.; Pescara, I. C.; Jardim, W. F.; Fernandes, A. N.; Sodré, F. F.; Almeida, F. V.; Santana, J. S., Canela, M. C.; et al. Sci. Total Environ., 2016, 572, pp 138-146 (http:// dx.doi.org/10.1016/j.scitotenv.2016.07.210).

30. Toyo'oka T. Modern Derivatization Methods for Separation Sciences. Wiley, 1999.

31. Mishra, A.; Vats, T.; Clark, J. H. Microwave-Assisted Polymerization. Royal Society of Chemistry, Cambridge, 2016, Chapter 1, pp 1-18 (https://doi.org/10.1039/9781782623182).

32. Pecoraro, É.; Davolos, M. R.; Jafelicci, Jr. M. Quim. Nova, 1997, 20 (1) pp 89-92.

33. Sequinel, R.; Hatanaka, R. R.; Gualtieri, C. E.; Flumignan, D. L.; De Oliveira, J. E.; Filho, J. P. Quim. Nova, 2010, 33, pp 2226-2232.

34. Davankov, V. A. Pure Appl. Chem., 2001, 73 (6), pp 969-992. Available at: http://old.iupac.org/ publications/pac/2001/pdf/7306x0969.pdf [Accessed: 10 January 2021].

35. Krahe, T.; Steudel, A.; Dewes, W.; Nicolas, V.; Klingmüller, D.; Lackner, K. RöFo - Fortschritte auf dem Gebiete der Rontgenstrahlen und der Nukl, 1987, 146 (5), pp 520-526.

36. Salihovic, S.; Nilsson, H.; Hagberg, J.; Lindström, G. TrAC - Trends Anal. Chem., 2013, 46, pp 129-138.

37. Fumes, B. H.; Andrade, F. N.; dos Santos Neto, Á. J.; Lanças, F. M. J. Sep. Sci., 2016, 39 (14), pp 2823-2830.

38. Riley, C. M. Prog. Pharm. Biomed. Anal., 1996, 3, pp 15-71 (https://doi.org/10.1016/S14643456(96)80004-4).

39. Huber, L. Validation and Qualification in Analytical Laboratories, $2^{\text {nd }}$ Edition. CRC Press, Boca Raton, 2013 (https://doi.org/10.3109/9780849382680).

40. Katsigiannis, A.; Noutsopoulos, C.; Mantziaras, J.; Gioldasi, M. Chem. Eng. J., 2015, 280, pp 49-57 (http://dx.doi.org/10.1016/j.cej.2015.05.109).

41. Kalas, F. A.; Carreira, R. S.; Macko, S. A.; Wagener, A. L. R. Cont. Shelf Res., 2009, 29 (19), pp $2293-$ 2302 (https://doi.org/10.1016/j.csr.2009.09.007).

42. Dévier, M. H.; Le Menach, K.; Viglino, L.; Di Gioia, L.; Lachassagne, P.; Budzinski, H. Sci. Total Environ., 2013, 443, pp 621-632 (http://dx.doi.org/10.1016/j.scitotenv.2012.10.015).

43. Rodrigues, I. O. Abrangência dos serviços de saneamento. In: Atlas de saneamento 2011, Instituto Brasileiro de Geografia e Estatística - IBGE, Rio de Janeiro, 2011.

44. Grimalt, J. O.; Fernández, P.; Bayona, J. M.; Albaigés, J. Environ Sci Technol., 1990, 24 (3) pp 357-363. 